\title{
A STUDY OF COMBUSTION AND ENGINE PERFORMANCE USING ELECTRONIC HYDROGEN FUEL INJECTION
}

\author{
K. S. VARde and G. M. Frame \\ Department of Mechanical Engineering, University of Michigan-Dearborn, Dearborn, MI 48128, U.S.A.
}

(Received for publication 7 April 1983)

\begin{abstract}
An experimental study was conducted using electronic hydrogen fuel injection in the intake manifold of a single cylinder spark-ignition engine. The purpose of the study was to investigate cyclic variations and backfiring and to determine if timed manifold injection provides any advantages over hydrogen carburation. It was found that injection improved cyclic pressure variations and practical lean operating range. A small improvement in thermal efficiency was also observed in the lean region. Based on limited work using timed port injection it seemed that backfiring could be controlled.
\end{abstract}

\section{NOMENCLATURE}

$\begin{array}{ll}\text { ABDC } & \text { After bottom dead center } \\ \text { ATDC } & \text { After top dead center } \\ \text { BBDC } & \text { Before bottom dead center } \\ \text { BTDC } & \text { Before top dead center } \\ \text { b.m.e.p. } & \text { Brake mean effective pressure } \\ \text { MBT } & \text { Minimum spark advance for best torque } \\ \Delta P & \text { Difference between peak cylinder pressure } \\ \tilde{P} & \text { Average of peak cylinder pressure } \\ \phi & \text { Equivalence ratio }\end{array}$

\section{INTRODUCTION}

In recent years there has been a growing interest to evaluate various alternative fuels that can be used to power spark-ignition engines. This has been stimulated either by concern over the increasing levels of air pollution in urban areas of industrial nations or by the need to decrease dependence on petroleum fuels and their projected cost or both.

Hydrogen has emerged as a potential fuel for internal combustion engines because of the following considerations:

(1) It is generally considered to be non-polluting. Since hydrogen contains no carbon, species such as carbon monoxide and unburned hydrocarbons, which are normally found in gasoline-fueled engines, would be virtually eliminated in the exhaust.

(2) Hydrogen is found in abundant quantities in various forms and can be considered to be almost an inexhaustible fuel.

(3) It can be adapted as a fuel to engines without major design changes in the powerplant, thereby taking advantage of the extensive research and development work that has gone in bringing the engine to its current state of reliability. This has been demonstrated in a number of studies (Finegold [2], Furuhama [3], Swain and Adt [9]).

A comparison of properties of hydrogen and gasoline (Varde and Lucas [10], Varde [11]), suggests that a hydrogen-fueled engine can be run on a much leaner equivalence ratio, $\phi$, than a gasoline-fueled engine (equivalence ratio $\phi$ is defined as the ratio of the stoichiometric air-fuel ratio to the actual air-fuel ratio). Generally, hydrogen-fueled engines have been run at a $\phi$ of 0.2-0.3 (Ricardo [7], King et al. [6], Stebar and Parks [8]) and in one particular case (Homan et al. [5]) a single cylinder CFR engine was run at values of $\phi$ as low as 0.03 by injecting hydrogen directly into the cylinder.

Although lean operation of a hydrogen-fueled engine can generally reduce $\mathrm{NO}_{x}$ emissions and show improved thermal efficiency, problems associated with operation can limit the practical range of $\phi$ that can be used in auto engines. A recent study by Drexl et al. [1] claims that a too lean mixture increases ignition delay and causes severe cyclic variations.

The problem of cyclic pressure variations is not new; gasoline-fueled engines suffer from this effect and as the air-fuel ratio is increased beyond stoichiometric the variations usually increase. It is generally believed that the primary cause of these variations is the turbulence in the combustion chamber. There is no doubt that turbulence is a major contributor to the phenomenon but it is also possible that cyclic variations in mixture quality contributes to pressure variations. Some of the experimental work conducted in our laboratory on gasoline-fueled engines has indicated this possibility.

Cyclic variations in the air-fuel mixture in conventional gasoline-fueled engines can arise because of problems associated with vaporization, wall wetting, etc., but in a gaseous hydrogen-fueled engine such variations can appear primarily as a result of variations in either the hydrogen flow rate, the air flow rate, or both. If cyclic variations in the quantity of metered fuel is kept low it may be possible to decrease the level of pressure variations generally observed in a hydrogen-fueled engine when operated on lean mixtures.

Another problem generally experienced in a carbureted hydrogen-fueled engine is the backfiring. Since minimum ignition energy for a hydrogen-air mixture at stoichiometric is over an order of magnitude lower than that for a gasoline mixture, localized hot points in the chamber and the temperature of residual gas are 
sometimes sufficient to cause backfiring. The latter can be avoided by direct hydrogen injection into the cylinder towards the end of the compression stroke (Furuhama and Azuma [4], Homan et al. [5]). Another approach would be to supply hydrogen into the intake manifold at a time when the suction process is already underway. The air inducted during the initial part of suction will cool hot points and residual gas. Hydrogen fuel entering the chamber during the latter part of suction will experience different and lower temperature which may inhibit backfiring.

To investigate this, a study was conducted on a single cylinder hydrogen-fueled engine where hydrogen was injected into the manifold by using an electronicallycontrolled fuel injector. The injection system utilized in the experiments was capable of injecting a pre-determined quantity of fuel with very small variations in fuel delivery from cycle to cycle. The specific objectives of this investigation were:

(1) To evaluate cyclic pressure fluctuations and determine if they can be lowered by using manifold fuel injection.

(2) To compare engine performance with and without fuel injection and see if there are benefits with manifold injection.

(3) To investigate the possibility of eliminating backfiring by late manifold injection.

\section{TEST EQUIPMENT}

A single cylinder, four stroke, spark-ignition engine was used in the experimental work. Table 1 shows the engine specifications and Fig. 1 shows the arrangement of the instrumentation. The engine (item (1) in Fig. 1) was coupled to a water brake dynamometer (2) for loading purposes. Water inlet pressure to the dynamometer was regulated to avoid load fluctuations during tests. An air-cooled Kistler pressure transducer (4) in a spark-plug adapter was installed in the cylinder head to measure cylinder pressure. The transducer amplifier output (5) was fed to a Tektronix oscilloscope (9) as well as to a sampler (10) where random cycles were selected to determine cyclic fluctuations in peak cylinder pressure during combustion. For each test point about 100 random cycles were sampled and analyzed. The cylinder head was also equipped with two ionization probes ( 7 and 8 ) to detect flame travel time (FTT) and the spread in flame speeds. The probes were located $36.8 \mathrm{~mm}$ apart and were operated at $150 \mathrm{~V}$ D.C. A pulse shaping circuit was used to shape the output from

Table 1. Engine specifications

Bore: $76.2 \mathrm{~mm}$

Stroke: $82.5 \mathrm{~mm}$

Compression ratio: $5.9: 1$

Spark gap: $1 \mathrm{~mm}$

Spark timing: MBT

Inlet valve timing: $35^{\circ} \mathrm{BTDC}-60^{\circ} \mathrm{ABDC}$

Exhaust valve timing: $65^{\circ} \mathrm{BBDC}-12^{\circ} \mathrm{ATDC}$

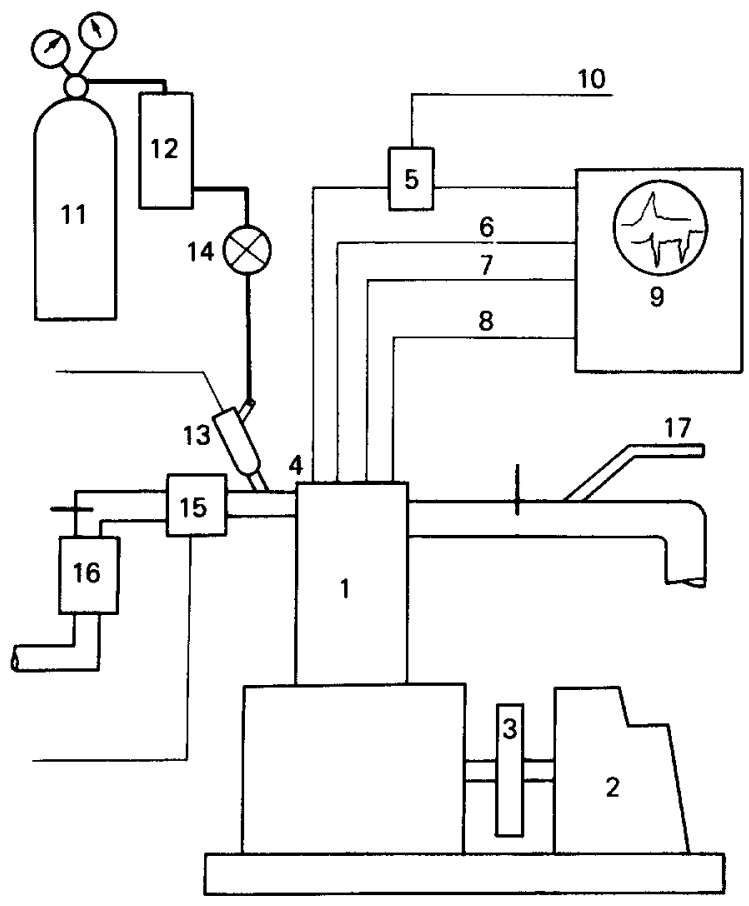

Fig. 1. (1) Engine, (2) dynamometer, (3) timing generator, (4) pressure transducer, (5) amplifier, (6) oscilloscope trigger, (7) and (8) ionization prober, (9) oscilloscope, (10) cycle sampling device, (11) hydrogen supply, (12) flowmeter, (13) injector, (14) valve and safety device, (15) carburetor, (16) air flow meter.

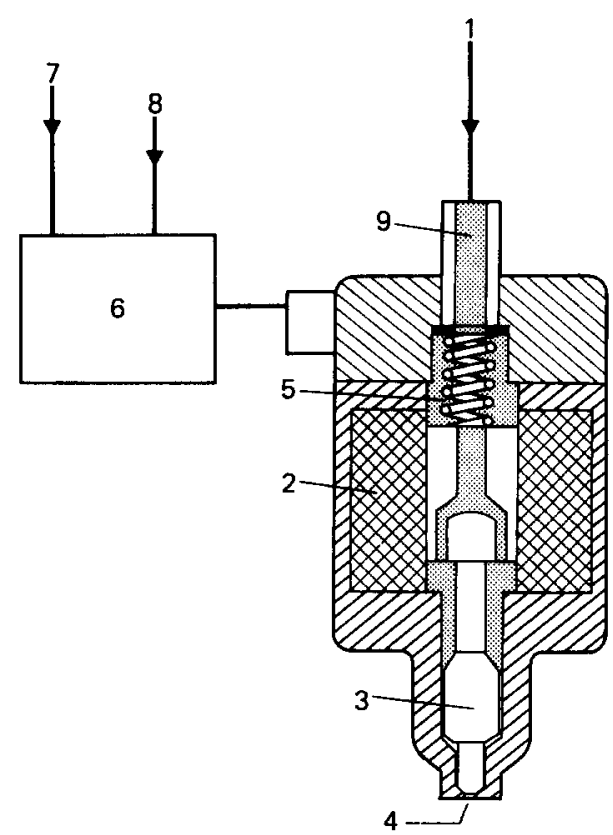

Fig. 2. (1) Hydrogen in, (2) coil, (3) plunger, (4) nozzle orifice, (5) preload spring, (6) injector controller, (7) signal input from magnetic sensor, (8) 12 V D.C. power in, (9) hydrogen flow path. 
the probes. By sampling a number of output pulses, it was possible to measure maximum and minimum flame speeds between the probes at various equivalence ratios.

Hydrogen gas was supplied to the engine either by carburetion or by manifold injection. In the case of injection bottled hydrogen gas of $99.95 \%$ purity (11) was throttled to a maximum of $300 \mathrm{kPa}$ pressure and supplied through a flowmeter (12) to the intake of the injector (13). Figure 2 shows some of the details of the injector and its control mechanism. The injector was controlled electronically so that the start of injection, injection duration and the end of injection could be controlled. A magnetic pick-up was used to generate a signal at the start of intake valve opening. The signal was supplied to the injector controller so that a current pulse supplied to the injector could be delayed with respect to this signal. This allowed an independent control of injection timing. Injection duration was controlled by varying the duration of the holding pulse supplied to the injector. Hydrogen flow rate to the engine was varied either by varying injection duration or the supply pressure to the injector. The injection periods selected were such that hydrogen fuel was injected only when the intake valve was open. With this arrangement, no hydrogen was allowed to remain in the intake manifold for the next induction period. In addition, hydrogen was injected close to the intake valve by recessing the injection nozzle in the manifold. The design of the injection nozzle and the plunger were such that the maximum flow rate achievable was much lower than needed to operate the engine near full load condition. Maximum flow rate was obtained when the hydrogen pressure at the injector was about $300 \mathrm{kPa}$. Hence the tests conducted in this investigation were limited to part-load operation. In most of the test reported here, the start of injection was kept fixed

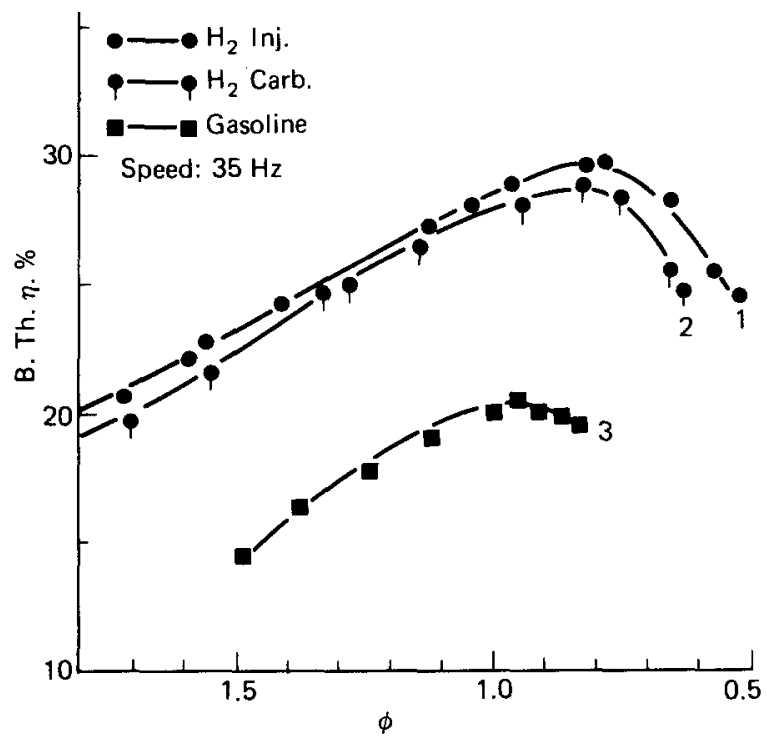

Fig. 3. Engine speed $35 \mathrm{~Hz}$. (1) Hydrogen injection, (2) hydrogen carburetion, (3) gasoline carburetion. corresponding to $20^{\circ} \mathrm{BTDC}$ and the injection duration was adjusted to match the desired flow rates.

Some experiments were also conducted with late lydrogen injection. In this case the start of injection 'vas fixed at $20^{\circ}$ ATDC, thus allowing hydrogen to flow into the chamber after some pure air was let in. Since the design of the injector limited hydrogen flow capability, experiments with late injection were limited in nature. Hence, the effect of late injection was used only to evaluate backfiring control. In the second method of fueling, namely, hydrogen carburation, hydrogen gas at a pressure slightly above atmospheric pressure was inducted in the intake manifold between the carburetor (15) and the intake valve. The flow rate was controlled by a fine metering valve (14) located between the flowmeter and the manifold.

For each test condition, exhaust gas samples were passed through a calibrated, chemiluminescent $\mathrm{NO}_{x}$ analyzer. Air flow rate into the engine was measured by a thin-film sensor flow meter (16); the flow was corrected for the conditions in the test cell. For each test, spark timing was adjusted for the MBT condition at the present engine speed. The engine was run at two speeds: 30 and $35 \mathrm{~Hz}$. Hydrogen flow rate was varied until the equivalence ratio was such that the engine misfired about $1 \%$ of the cycles. The engine was run at a brake mean effective pressure of about $200 \mathrm{kPa}$ corresponding to stoichiometric operation when the injection timing was $20^{\circ} \mathrm{BTDC}$ and at about $125 \mathrm{kPa}$ for the same mixture strength when late injections were used.

\section{RESULTS AND DISCUSSION}

The effects of different methods of fueling on the engine thermal efficiency are shown in Figs 3 and 4.

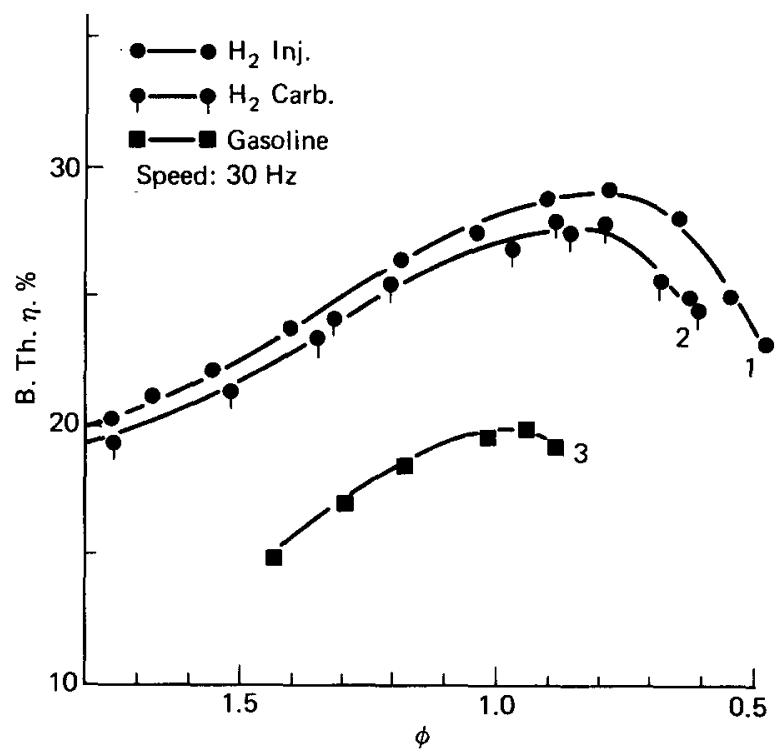

Fig. 4. Engine speed $30 \mathrm{~Hz}$. (1) Hydrogen injection, (2) hydrogen carburetion, (3) gasoline carburetion. 
For comparison purposes, the efficiencies obtained with gasoline carburetion of the same engine are also shown. It is clear that the engine could be run on a much wider range of equivalence ratios when fueled by hydrogen than with gasoline. In addition, there is a marked increase in efficiency with hydrogen fuel. Even at high or low equivalence ratios, the hydrogen-fueled engine generally yielded a higher thermal efficiency than the best possible with gasoline.

Of the two methods of hydrogen supply used in the engine operation, fuel injection showed a great improvement in efficiency over carburetion but the real difference was realized in the value of the lowest equivalence ratios at which the engine could be run satisfactorily. Although Figs 3 and 4 show a lean equivalence ratio limit of about 0.5 for injection, it was possible to run the engine at about $\phi=0.35$. However, the power developed by the engine was very low. The lowest value of $\phi$ at which the engine could be run was higher than generally found in other hydrogen-fueled engines. The reason for this may be inadequate mixing of air and hydrogen fuel caused by supplying fuel near the intake valve. When carburetion was used the leanest value of $\phi$ at which the engine ran smooth was about 0.5 . Both of the methods showed engine brake thermal efficiency to peak around $\phi=0.7$. This equivalence ratio is higher than those claimed by others (Homan, 1979, Stebar and Parks [8]) but the present work was conducted at part loads where pumping and frictional losses absorb a disproportionate portion of the power developed by the engine.

Emissions of oxides of nitrogen in the exhaust are shown in Fig. 5. As expected, peak $\mathrm{NO}_{x}$ appears for $\phi$ slightly less than unity and drops off on either side. Formation and emission of $\mathrm{NO}_{x}$ is highly dependent on temperature in the combustion chamber and on the

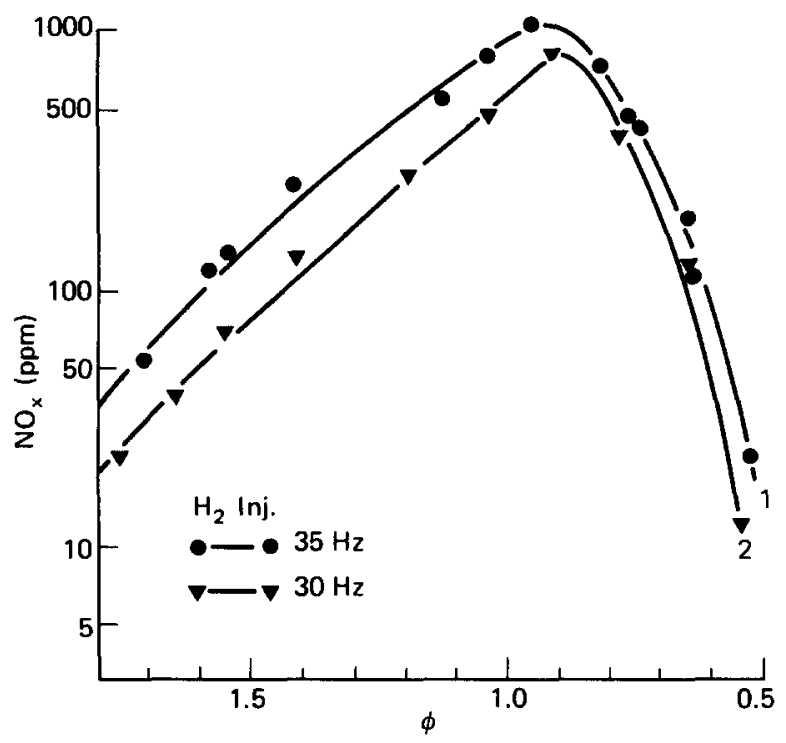

Fig. 5. Hydrogen injection. Speed (1) $35 \mathrm{~Hz}$, (2) $30 \mathrm{~Hz}$.

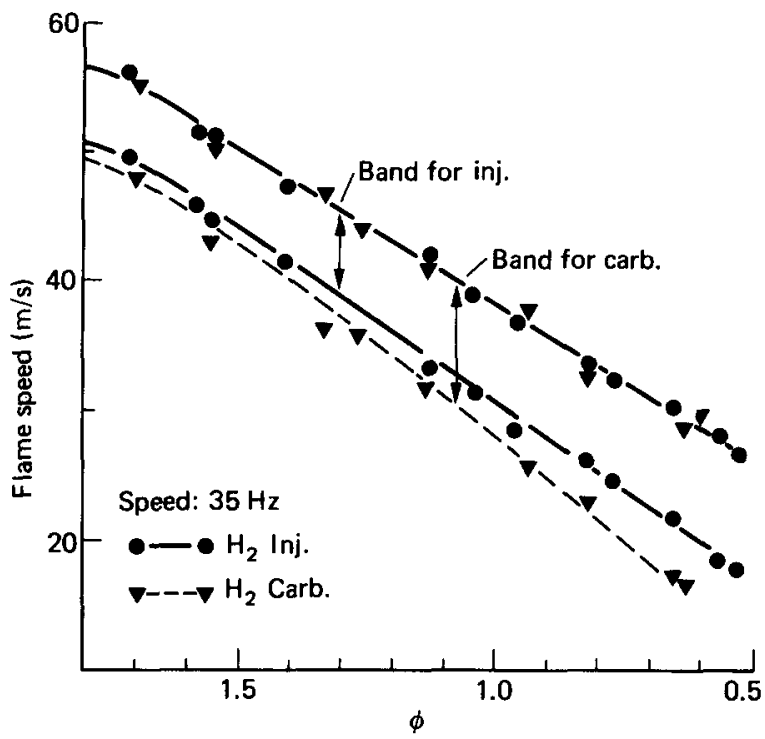

Fig. 6. Engine speed $35 \mathrm{~Hz}$.

mixture strength. As the mixture air-fuel ratio gets leaner, the temperature drops and $\mathrm{NO}_{x}$ formation kinetics get weaker. For the same mixture strength $\mathrm{NO}_{x}$ emission is slightly higher for higher engine speed because of reduced effective heat loss. When the engine was run on carbureted hydrogen, $\mathrm{NO}_{x}$ emissions did not differ much from those shown in Fig. 5. However, for carbureted mixtures the MBT spark timing was about 2-4 crank degrees advanced than for the electronically injected hydrogen, particularly for $\phi<0.9$. Since advanced spark tends to increase temperature in the burned gas, $\mathrm{NO}_{x}$ emission generally increases with spark advance. Considering the MBT spark timing for the two methods and the $\mathrm{NO}_{x}$ levels, it seems that the hydrogen injection method produces a slightly higher

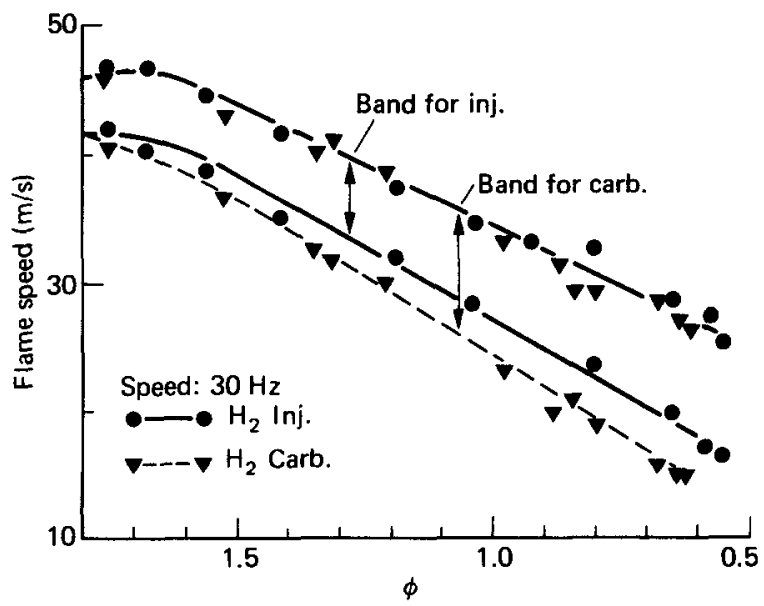

Fig. 7. Engine speed $30 \mathrm{~Hz}$. 
temperature in the chamber. This can be attributed to faster burning of the mixture in the chamber.

In fact, measurement of flame speeds in the combustion chamber does show average speeds to be higher for hydrogen injection than for carburetion (Figs 6 and 7). The band for each method was based on the maximum and minimum speed between the two probes measured for over 100 randomly selected cycles. For any given speed, the band widened as the equivalence ratio decreased. It is also apparent that the spread in flame speed increased at a faster rate for carburetion than for injection for values of $\phi<1$.

Flame speed variations have been observed in all spark-ignition engines and are claimed to be primarily caused by turbulence in the chamber. It is possible that cyclic variations in air-fuel ratio may also contribute to flame speed variations. As the air-fuel ratio varies, the energy content in the cylinder varies and hence the flame speed and pressure developed in the chamber vary. For a given $\phi$ and engine speed, turbulence in the chamber is expected to be the same for both the methods of hydrogen supply used in this investigation. But the variations in flame speed are higher for carburetion than for injection (for $\phi<1$ ) suggesting that air-fuel ratio variations also contribute to cyclic variations. To a certain degree, cyclic variations in a hydrogen-fueled engine can be lowered by controlling variations in $\phi$, as was done in the present study using electronic injection. For all the operating conditions, maximum flame speed was found for values of $\phi$ between 1.6 and 1.8. Although the combustion period at these equivalence ratios is greatly reduced the mixture is deficient in oxygen and, hence $\mathrm{NO}_{x}$ concentration in the exhaust is low. Reducing $\phi$ from about 1.7 to 0.5 reduces the average flame speed by about $50 \%$ or over. Thus the spark timing had to be advanced to compensate for long combustion duration.

The effects of hydrogen injection and lean operation

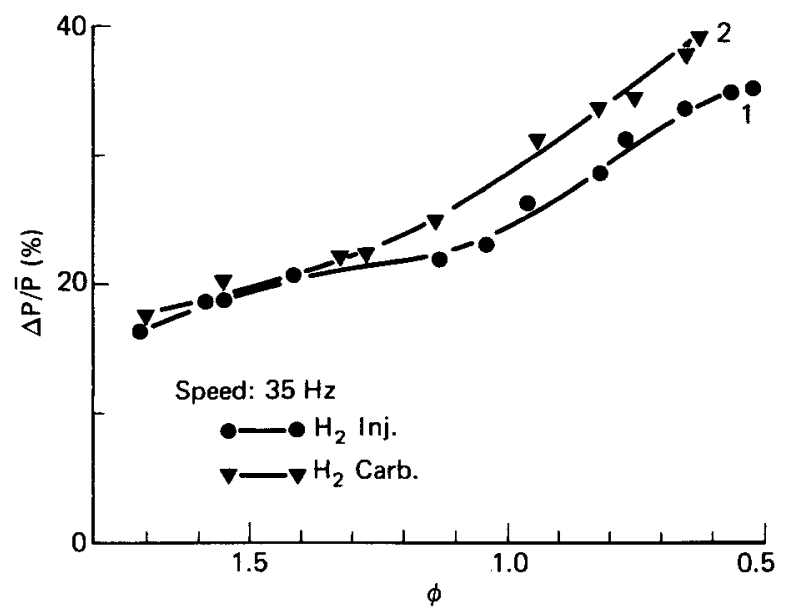

Fig. 8. Engine speed $35 \mathrm{~Hz}$. (1) Hydrogen injection, (2) hydrogen carburetion.

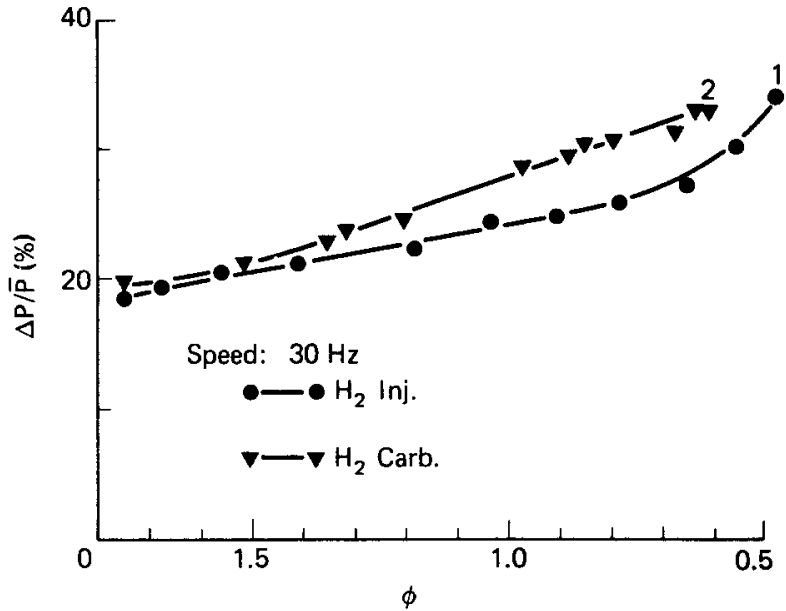

Fig. 9. Engine speed $30 \mathrm{~Hz}$. (1) Hydrogen injection, (2) hydrogen carburetion.

on cyclic pressure variations are shown in Figs 8 and 9. Since the peak cylinder pressure decreases as $\phi$ gets leaner, cyclic pressure variations are shown in terms of a non-dimensional parameter, $\Delta P / \bar{P}$. The value of $\Delta P$ is based on the maximum and the minimum values of peak cylinder pressure and $\bar{P}$ is based on the average peak cylinder pressure of the sampled cycles. Cyclic pressure fluctuations increase as the equivalence ratio gets leaner. In addition, it can be observed from the figures that injecting fuel produces lower variations than carburetion. Not much difference in pressure variations was observed between the two methods when the engine was run with fuel rich mixtures but as mixture strength decreases beyond stoichiometric $\Delta P / \bar{P}$ starts to exhibit the effect of hydrogen induction method. It appears that $\Delta P / \bar{P}$ is almost related to percentage variations in flame speed and by reducing variations in mixture strength it is possible to lower cyclic pressure variations in the lean mixture region. As the mixture gets leaner, the ratio of flame speed fluctuations to the average flame speed increases as a result of turbulence and inhomogeneity; this results in increased pressure variations. Even if cyclic variations in air-fuel ratio are eliminated for a given average $\phi$, cyclic pressure variations cannot be avoided but can be decreased relative to uncontrolled air-fuel ratio operation. Thus, manifold fuel injection shows a lower $\Delta P / \bar{P}$, as seen in the figures.

When the engine was run on hydrogen carburetion, backfiring was noticed between $\phi=1.15$ and 0.9 . With manifold injection the range of $\phi$ for backfiring decreased to between 1.1 to almost stoichiometric when the start of injection was $20^{\circ} \mathrm{BTDC}$. At this injection timing hydrogen fuel gets into the cylinder when residual gases and localized spots are still hot. In addition, around $\phi=1$ the minimum ignition energy for hydrogen mixture is only about $20 \mu \mathrm{J}$, which can be found in the cylinder. The fact that the $\phi$ range decreased for the injection method can be attributed to the absence of 
hydrogen gas in the intake manifold during the remainder of the cycle.

Some experiments were conducted at lower b.m.e.p. and $35 \mathrm{~Hz}$ by delaying the start of injection by about 40 crank degrees (late injection) and a comparison of backfiring was made for early injection ( $20^{\circ}$ BTDC). In the latter case the engine was also run at $35 \mathrm{~Hz}$ and developed a b.m.e.p. almost the same as with late injection. It was noticed that late injection virtually eliminated backfiring; in fact, backfiring occurred only occasionally, indicating that late manifold injection might help to eliminate backfiring even at full load conditions if the injector can deliver the necessary flow rate.

It would be interesting to see if backfiring can be completely eliminated at all engine loads and speeds by injecting fuel in the intake manifold during the later part of the suction stroke when residual gases and cylinder walls have sufficiently been cooled by the incoming air. Electronic fuel injection also provides an easy method to change injection timing and fuel delivery rate and may help to run a hydrogen-fueled engine at the best operating points.

\section{CONCLUSIONS}

Cyclic variations in mixture strength could be reduced by injecting hydrogen in the intake manifold. The effect of this was to decrease the band of flame speed variations in the lean mixture region and consequently reduced cyclic pressure variations. Hydrogen injection also allowed the engine to operate on a leaner equivalence ratio than a carbureted engine. It was found that backfiring can be avoided by injecting hydrogen late during the suction process when the residual gases have been cooled by the fresh intake air.

\section{REFERENCES}

1. K. W. Drexl, H. Holz and M. Gutmann, Characteristics of a Single Cylinder Hydrogen Fueled IC. Engine Using Various Mixture Formation Methods. Report of Daimler-Benz AG, Central Research, Germany (1977).

2. J. A. Finegold et al., The UCLA Hydrogen Car: Design and Construction and Performance. SAE Paper 730507 (1973).

3. S. Furuhama et al., Combustion Improvement in a Hydrogen Fueled Engine. Int. J. Hydrogen Energy 2, 329 (1977).

4. D. Furuhama and H. Azuma, Hydrogen Injection TwoStroke Spark Ignition Engine. Proc. 2nd World Hydrogen Energy Conference, Vol. IV (1978).

5. H. S. Homan, P. C. T. deBoer and W. J. McLean, The Effects of Fuel Injection on NOx Emissions and Undesirable Combustion for Hydrogen-Fueled Piston Engines. SAE Papẹr 780945 (1978).

6. R. O. King et al., The Hydrogen Engine: Combustion Knock and Related Flame Velocity. Trans. Engng. Inst. Canada 2, (4) (1958).

7. H. R. Ricardo, Further Note on Fuel Research. Proc. Automobile Engr (Lond.) 18 (1923).

8. R. F. Stebar and F. B. Parks, Emission Control with Lean Operation Using Hydrogen Supplemented Fuel. SAE Paper 740187 (1974).

9. M. R. Swain and R. R. Adt, Jr., The Hydrogen-Air Fueled Automobile. Proc. 7th IECEC, California, U.S.A. (1972).

10. K. S. Varde and G. G. Lucas, Hydrogen as a Fuel for Vehicle Propulsion. Proc. Instn. mech. Engrs. 188, 365372 (1974).

11. K. S. Varde, Combustion Characteristics of Small S.I. Engines Using Hydrogen Supplemented Fuel Mixtures. SAE Paper 810921 (1981). 